\title{
Genetic selection against intrauterine growth retardation in piglets: a problem at the piglet level with a solution at the sow level
}

\author{
Stephanie M. Matheson ${ }^{1 *}$, Grant A. Walling ${ }^{2}$ and Sandra A. Edwards ${ }^{1}$
}

\begin{abstract}
Background: In polytocous livestock species, litter size and offspring weight act antagonistically; in modern pig breeds, selection for increased litter size has resulted in lower mean birth weights, an increased number of small piglets and an increased number of those affected by varying degrees of intrauterine growth retardation (IUGR). IUGR poses life-long challenges, both mental, with morphological brain changes and altered cognition, and physical, such as immaturity of organs, reduced colostrum intake and weight gain. In pigs, head morphology of newborn piglets is a good phenotypic marker for identifying such compromised piglets. Growth retardation could be considered as a property of the dam, in part due to either uterine capacity or insufficiency. A novel approach to this issue is to consider the proportion of IUGR-affected piglets in a litter as an indirect measure of uterine capacity. However, uterine capacity or sufficiency cannot be equated solely to litter size and thus is a trait difficult to measure on farm.

Results: A total of 21,159 Landrace $\times$ Large White or Landrace $\times$ White Duroc piglets (born over 52 weeks) with recorded head morphology and birth weights were followed from birth until death or weaning. At the piglet level, the estimated heritability for IUGR (as defined by head morphology) was low at $0.01 \pm 0.01$. Piglet direct genetic effects of birth weight ( $h^{2}=0.07 \pm 0.02$ ) were strongly negatively correlated with head morphology $(-0.93)$, in that IUGR-affected piglets tended to have lower birth weights. At the sow level, analysis of the proportion of IUGR-affected piglets in a litter gave a heritability of $0.20 \pm 0.06$, with high and negative genetic correlations of the proportion of IUGR-affected piglets with average offspring birth weight $(-0.90)$ and with the proportion of piglets surviving until $24 \mathrm{~h}(-0.80)$.
\end{abstract}

Conclusions: This suggests that the proportion of IUGR-affected piglets in a litter is a suitable indirect measure of uterine capacity for inclusion in breeding programmes that aim at reducing IUGR in piglets and improving piglet survival.

\section{Background}

The antagonistic life-history trade-off between litter size and offspring size [1-4] originates from the allocation of limited maternal reserves, i.e. energy, nutrients, and abdominal space available for offspring [5]. In polytocous livestock species, litter size is studied in order to

\footnotetext{
*Correspondence: stephanie.matheson@newcastle.ac.uk

1 Agriculture, School of Natural and Environmental Sciences, University

of Newcastle, Newcastle upon Tyne NE1 7RU, UK

Full list of author information is available at the end of the article
}

increase prolificacy, which is the result of complex interactions between male, female, and embryo genotypes [6], although genetic or permanent environmental factors are of low importance due to the high variability in litter size [7]. The success of selection for high prolificacy may be due largely to an increase in the number of corpora lutea $[8,9]$, with associated negative consequences for the resulting foetal-placental units [9-11]. Indeed, in pigs, it has been shown that selection for increased litter size leads to a significantly lower mean birth weight and a greater percentage of small piglets born [12, 13], with 
the possibility of various degrees of intrauterine growth retardation occurring in these small piglets [14].

In pigs, intrauterine growth retardation (IUGR) has been associated with impaired foetal and placental growth [15], which can result in lower birth weights and a higher brain to liver weight ratio [16] due to the 'brainsparing effect.' This is part of a foetal adaptive reaction to placental or nutritional insufficiency [17], which may have permanent effects on the structure, physiology and metabolism of the body $[18,19]$, intestinal morphology and enzyme secretion [20-22]. Wang et al. [23] showed that proteins related to energy supply, protein metabolism and muscle structure, function and proliferation are differentially expressed in IUGR-affected piglets, which indicates impaired metabolism and reduced growth and development of muscle. Thus, IUGR poses economic problems for subsequent commercial meat production, such as reduced feed conversion efficiency and a decreased percentage of meat [24] and increased percentage of body fat in the carcass [25].

One suggested solution to reduce the incidence of IUGR-affected piglets due to gestational-undernutrition is to provide the sow with a nutritional intervention during pregnancy [26, 27]. However, some studies have found that increasing global maternal nutrition has no effect on piglet performance and muscle traits [28], while other studies observed that both maternal under-nutrition and over-nutrition may stunt foetal growth [29, 30].

An alternative approach to reduce IUGR is to select against the IUGR phenotype, either directly at the piglet level or at the maternal level. Some easily classified fitness traits at the offspring level are heritable and suitable for direct selection, i.e. offspring vitality or vigour [31, 32]. In pigs, as in other polytocous species (e.g. rats [33]), IUGR-affected offspring display a phenotype that is easy to categorise, i.e. an altered head morphology [34, 35] with three characteristics: (1) a steep, dolphin-like forehead, (2) bulging eyes, and (3) wrinkles perpendicular to the mouth.

Although the foetal genome is an important factor for growth potential in utero, there is evidence that suggests that the intrauterine environment is a major determinant of foetal growth [30]. In this case, if selection at the piglet level is not effective, selection at the maternal level could be based on the proportion of IUGR-affected piglets in a litter. Bazer et al. [36, 37] showed that greater embryonic loss, which is associated with a larger number of embryos in the uterus, is due to maternal limitations and not to limitations of the embryo. The proportion of IUGR-affected piglets in a litter may depend, in part, on the available uterine capacity, which can be defined as the ability of the uterus to maintain the appropriate development of some number of conceptuses [38]. However, uterine capacity, as defined by Webel and Dzuik [39], is difficult to measure directly on farm but the proportion of IUGR-affected piglets in a litter could be an indirect measure that could be used for selection.

The amount of genetic variation in head morphology of IUGR-affected piglets at the piglet and sow levels can be compared by estimating either the narrow-sense heritability, $h^{2}$, i.e. the standardised additive genetic variance, $V_{g}$, or the evolvability, $I_{A}$, i.e. the square of the coefficient of the additive genetic variance, $I_{A}=100 \times V_{g} /$ mean $^{2}$ [40]. The evolvability of a trait refers to the ability of a population to respond to a potential selective challenge [41], i.e. its ability to generate adaptive genetic diversity, and is equal to the "expected percent change in a trait under a unit strength of selection" [42]. Therefore, the evolvability of a trait refers to the capacity of a population to generate heritable and selectable phenotypic variation [43], which suggests that a greater evolvability allows for greater selection possibilities. $I_{A}$ is a mean-scaled and dimensionless statistic, like narrow-sense heritability, $h^{2}$, and, thus, is also suitable for the comparison of traits at both the maternal and offspring level.

Thus, the objective of this study was to determine if the incidence of immature piglets could be reduced by: (1) selection at the piglet level by recording IUGR head morphology of IUGR-affected piglets used as an indirect measure for IUGR; or (2) selection at the sow level based on the proportion of IUGR-affected piglets born in a litter, as a candidate for indirect measurement of uterine insufficiency.

\section{Methods}

This study was conducted in accordance with the Newcastle University Ethics Policy for Research, Teaching and Consultancy. All pigs were maintained in accordance with the Welfare of Farmed Animals (England) Regulations 2007.

\section{Animals}

Data were collected for 52 weeks in 2015 and 2016 on 21,159 piglets from 1575 litters (866 individual sows) at a commercial multiplier sow herd located in the UK, which produces crossbred gilts. The unit consists of a sow herd of approximately 750 Landrace sows, which are inseminated artificially with either White Duroc or Large White semen. At insemination, animals in standing oestrus were served up to 3 times at 12- to 14-h intervals with a semen dose of 2.7 billion spermatozoids. The decision of whether to serve an animal for a third time depended on whether it still demonstrated standing oestrus.

During gestation, animals were fed on a standard gestation curve according to the season. In the summer months (April-September), gilts were given $2.2 \mathrm{~kg}$ sow 
meal post-service and $2.5 \mathrm{~kg}$ prior to farrowing, whereas sows were given $2.5 \mathrm{~kg}$ sow meal at service and $3.0 \mathrm{~kg}$ sow meal at farrowing. During the winter months (October-March), gilts were given $2.5 \mathrm{~kg}$ sow meal at service and $3.0 \mathrm{~kg}$ sow meal at farrowing, with sows receiving an additional $0.5 \mathrm{~kg}$ compared to the gilts. Each ration contained crude protein at $10.50 \%$, oils/fats at $5.25 \%$, crude fibre at $4.25 \%$, crude ash at $4.75 \%$, and digestible lysine at $0.43 \%$. The net energy of the ration was $9.35 \mathrm{MJ} / \mathrm{kg}$.

\section{Animal husbandry}

After insemination, sows were group-housed in gestation pens and remained in their gestation pen cohorts until shortly before farrowing, except for those removed because of lameness or aggression issues. During farrowing (and until weaning), sows and piglets were maintained in standard farrowing crates $(0.62 \times 2.40 \mathrm{~m})$, with a heated piglet area (heated mat or heat lamp) to the front or side of the sow. In general, no assistance was required during farrowing, except in the case of prolonged birth, and all piglets remained in their birth litters until processing at 18-24 $\mathrm{h}$ after farrowing, when piglets were first handled for tail docking, teeth grinding and ear tagging for identification of females (males were not identified). All piglets were then cross-fostered to equalize the number and size of piglets in a litter and maximise chances of survival by mixing all piglets born on the same day and then allocating them by size to the available sows.

\section{Data collection}

For sows, data collection included parity, gestation length (GL), total litter size (LITTER SIZE i.e. the number of full-term piglets born alive + born dead, but not including mummified piglets), and the numbers of piglets born alive, born dead, and mummified. Data collected at the piglet level included sex, individual piglet weight at processing (Ind BWT; used as a proxy for birth weight), and the level of exposure to IUGR.

The level of IUGR a piglet was exposed to was determined by the shape of the head, using visual scores based on head morphology [34] and three criteria that characterise growth-restricted piglets [35], i.e. (1) steep, dolphin-like forehead; (2) bulging eyes; and (3) wrinkles perpendicular to the mouth. Using these criteria, the following three-point piglet head-morphology score was used: $1=$ normal head shape, no criteria met; $2=$ moderate IUGR head morphology, one or two criteria met; and $3=$ severe IUGR head morphology, all criteria met. These scores were then further condensed into either a normal head shape (score 1) or an IUGR head morphology (scores 2 and 3 combined), which translated into the following traits: (1) at the piglet level, whether the piglet was born with a normal head shape or an IUGR head morphology (HEAD CLASS); and (2) at the sow level, the number of piglets with a HEAD CLASS of 1, which resulted in the proportion of piglets in a litter with an IUGR head morphology (PROP IUGR). For each litter, the average birth weight (AVE BWT), the standard deviation of birth weight (SD BWT), and the proportion of the litter (born alive and born dead) that survived to processing (18-24 $\mathrm{h}$ after birth; PROP SURV) were calculated.

\section{Statistical analyses}

All genetic parameters, predicted means for the fixed effects, and covariance parameters for covariates at both the piglet and sow levels were obtained using mixed linear models in ASReml [44]. Traits analyzed included the binary trait HEAD CLASS at the piglet level, which was not transformed before analysis and although there are statistically more rigorous mathematical algorithms based on assumptions of ordered categories and concepts of thresholds [45-47], the general linear model has been shown to be an appropriate approximation [48].

Traits of interest at the piglet level were HEAD CLASS [normal (0) or IUGR (1)] and birth weight (Ind BWT). A bivariate mixed linear model was used that included fixed effects for sow parity (1-6+), piglet sex [male (M) or female (F)], presence of mummified piglets within the litter (Yes/No), month of birth, and the covariates of litter size and gestation length. Random effects were the direct additive genetic effect, the permanent environmental effect of the dam, and the residual.

Traits of interest at the sow level were PROP IUGR, AVE BWT, SD WBT, LITTER SIZE, PROP SURV, and GL. A 6-variate mixed linear model was used with fixed effects for sow parity, farrowing month, and the covariate of gestation length. Random effects were the additive genetic effect (variance $V_{g}$ ), permanent environmental effect (variance $V_{p e}$ ), and the residual (variance $V_{r}$ ) of the sow. Repeatability was calculated as: $P=\left(V_{g}+V_{p e} / V_{p}\right)$, where $V_{p}$ is the phenotypic variation of the trait. It should be noted that piglet genotype $(\mathrm{L} \times \mathrm{LW}$ or $\mathrm{L} \times \mathrm{WD})$ was initially included in the analysis but since it was not significant $(P>0.1)$, it was removed from the model.

$\begin{aligned} & \text { Table } 1 \text { Pedigree structure for datasets at the piglet } \\
& \text { and sow levels }\end{aligned}$
\begin{tabular}{lcccc}
\hline Dataset & Records & Sires $^{\mathbf{a}}$ & Dams $^{\mathbf{a}}$ & $\begin{array}{l}\text { Total } \\
\text { pedigree } \\
\text { size }\end{array}$ \\
\hline Piglet level & 21,159 & 58 & 861 & 23,436 \\
Sow level & 1575 & 133 & 438 & 2104 \\
\hline
\end{tabular}

a Number of sires or dams with offspring with records 
Table 2 Data summary at the piglet and sow levels

\begin{tabular}{llll}
\hline Trait & N & Mean & SD \\
\hline Piglet level & & & \\
HEAD CLASS (0/1) & 20,991 & 0.1614 & 0.3679 \\
Ind BWT (g) & 21,147 & 1453 & 370.3 \\
Sow level & & & \\
PROP IUGR & 1575 & 0.1445 & 0.1528 \\
Ave BWT (g) & 1575 & 1493 & 261.5 \\
SD BWT (g) & 1575 & 278.2 & 89.32 \\
LITTER SIZE & 1575 & 13.45 & 3.684 \\
PROP SURV & 1575 & 0.9013 & 0.1287 \\
GL (days) & 1575 & 114.9 & 1.260 \\
\hline
\end{tabular}

Traits at the piglet level: HEAD CLASS = head morphology (normal or IUGR) and Ind BWT = individual birth weight

Traits at the sow level: PROP IUGR= proportion of piglets with an IUGR head morphology within a litter, AVE BWT = average birth weight within a litter, SD BWT = within-litter standard deviation in birth weight, litter size, PROP $\mathrm{SURV}=$ proportion of a litter surviving to processing, and $\mathrm{GL}=$ gestation length $S D$ standard deviation

The pedigree structure that was used for the models at the piglet and sow levels is in Table 1. It should be noted that the pedigree structure did not allow separation of maternal additive effects, maternal permanent environmental effects and temporary environmental effects for any of the piglet level traits.

\section{Results}

Summarized data for the piglet and sow levels are in Table 2. For the 1575 farrowings that were included in the study, 330 sows had one record, 345 two records and 185 three records. Parity ranged from 1 to 9 , with $420,322,252,223,172,97,65,20$, and 4 litters, respectively. At the piglet level, more piglets were born with a normal HEAD-CLASS score (score $0 ; n=17,604$ ) than with an IUGR HEAD score (score $1 ; \mathrm{n}=3387$ ), and Ind BWT ranged from 178 to $2960 \mathrm{~g}$. At the litter level, there were $475 \mathrm{l}$ with no piglets showing IUGR head morphology (PROP IUGR $=0$ ). Ave BWT of a litter ranged from 820 to $2740 \mathrm{~g}$ and the SD BWT ranged from 8.5 to 811.8 g. LITTER SIZE ranged from 1 to 29 piglets. The within-litter proportion of piglets surviving to processing (18-24 h; PROP SURV) ranged from 0.086 to 1 and GL ranged from 106 to $120 \mathrm{~d}$.

For all traits, month of birth was a significant source of variation but these results are not presented since month of birth and any differences in management are not repeatable and are therefore of limited interest.

\section{Fixed effects for traits at the piglet level}

Male piglets had a lower (more normal) HEAD CLASS score and were heavier at birth than female piglets
Table 3 Effects of piglet sex and presence of at least one mummified litter mate on traits at the piglet level

\begin{tabular}{llll}
\hline Piglet sex & Male & Female & P value \\
\hline HEAD CLASS & $0.168 \pm 0.009$ & $0.194 \pm 0.009$ & 0.005 \\
Ind BWT (g) & $1452 \pm 16$ & $1411 \pm 16$ & $<0.001$ \\
\hline $\begin{array}{l}\text { Mummified litter } \\
\text { mate }\end{array}$ & No & Yes & P value \\
\hline HEAD CLASS & $0.168 \pm 0.009$ & $0.193 \pm 0.0111$ & 0.040 \\
Ind BWT (g) & $1452 \pm 15$ & $1411 \pm 17$ & 0.007 \\
\hline
\end{tabular}

HEAD CLASS $=$ head morphology (score $=0$ normal to 1 IUGR head morphology) Ind BWT = individual birth weight

All standard errors ( \pm SEM) are from a 2-variate model

(Table 3). Piglets from primiparous sows had a higher abnormal HEAD CLASS score than piglets from later parity sows (Table 4). Piglets from second parity sows had the lowest HEAD CLASS score, which then increased with successive parities. Ind BWT was lowest for primiparous sows, highest for second and third parity sows, and then decreased with successive parities (Table 4).

Piglets from larger litters had a higher abnormal HEAD CLASS score (regression coefficient \pm SEM, $0.017 \pm 0.001, P<0.001$ ) and lower Ind BWT (regression coefficient \pm SEM, $-40.26 \pm 1.03, P<0.001)$ than piglets from smaller litters. Piglets from a litter that had one (or more) mummified piglets had a higher abnormal HEAD CLASS score and lower Ind BWT than piglets from litters without mummified piglets (Table 3 ).

\section{Heritabilities for traits at the piglet level}

The bivariate genetic analysis for traits at the piglet level was conducted on the full dataset of 21,159 records, of which, 20,991 piglets had both HEAD CLASS and Ind BWT records. For HEAD CLASS and Ind BWT, the permanent environmental effect of litter accounted for 5 and $15 \%$ of the phenotypic variance, respectively, while direct additive genetic effects for 5 and $20 \%$ of the phenotypic variance, respectively (Table 5 ). The residual accounted for 90 and $65 \%$ of the phenotypic variance, respectively.

Estimates of direct heritability for HEAD CLASS score and Ind BWT were low, i.e. $0.01 \pm 0.001$ and $0.07 \pm 0.023$, respectively (Table 5 ). The genetic correlation between these traits was high and negative, i.e. $0.93 \pm 0.05$. HEAD CLASS had a low $I_{A}$ of $7.7 \%$ and Ind BWT had a very low $I_{A}$ of $0.4 \%$. The maternal heritability for HEAD CLASS was also low at $0.03 \pm 0.009$ but was slightly higher for Ind $\mathrm{BWT}$ at $0.11 \pm 0.028$. 
Table 4 Effect of sow parity on traits at the piglet level

\begin{tabular}{|c|c|c|c|c|c|c|}
\hline Sow parity & 1 & 2 & 3 & 4 & 5 & $6+$ \\
\hline HEAD CLASS & $0.214 \pm 0.011^{a}$ & $0.148 \pm 0.011^{c}$ & $0.158 \pm 0.011^{c}$ & $0.180 \pm 0.011^{b}$ & $0.184 \pm 0.012^{b}$ & $0.200 \pm 0.013^{a b}$ \\
\hline Ind BWT (g) & $1306 \pm 18^{c}$ & $1473 \pm 17^{a}$ & $1476 \pm 17^{\mathrm{a}}$ & $1456 \pm 17^{\mathrm{a}}$ & $1449 \pm 18^{a}$ & $1427 \pm 19^{b}$ \\
\hline
\end{tabular}

HEAD CLASS $=$ head morphology (score $=0$ normal to 1 IUGR head morphology)

Ind BWT = individual birth weight

All standard errors ( \pm SEM) are from bivariate model analyses of HEAD CLASS and Ind BWT

Within a line in the table, mean values that share the same character in superscript $(a, b$ or $c)$ do not differ significantly $(P>0.05)$

Table 5 Estimates of phenotypic variance $\left(V_{p}\right)$, residual variance $\left(V_{r}\right)$, direct additive genetic variance $\left(V_{g}\right)$, maternal genetic variance $\left(V_{m}\right)$, common environmental effects within litter variance $\left(V_{e}\right)$, of direct and maternal heritability (in italics on diagonal), and of genetic correlations (below diagonal) for traits at the piglet level

\begin{tabular}{lll}
\hline & HEAD CLASS & Ind BWT \\
\hline$V_{p}$ & $0.131 \pm 0.001$ & $119,480 \pm 2290$ \\
$V_{r}$ & $0.121 \pm 0.001$ & $86,549 \pm 1761$ \\
$V_{g}$ & $0.002 \pm 0.002$ & $8822 \pm 2970$ \\
$V_{m}$ & $0.004 \pm 0.001$ & $12,313 \pm 3420$ \\
$V_{e}$ & $0.004 \pm 0.001$ & $11,793 \pm 2614$ \\
Direct heritability for HEAD CLASS & $0.01 \pm 0.007$ & \\
Direct heritability for Ind BWT & $-0.90 \pm 0.099$ & $0.07 \pm 0.024$ \\
Maternal heritability for HEAD CLASS & $0.03 \pm 0.009$ & \\
Maternal heritability for Ind BWT & $-0.85 \pm 0.077$ & $0.10 \pm 0.028$ \\
Direct evolvability & $7.68 \%$ & $0.42 \%$
\end{tabular}

HEAD CLASS $=$ head morphology (score $=0$ normal to 1 IUGR head morphology) Ind BWT = individual birth weight

All standard errors ( \pm SEM) are from a 2-variate model

\section{Fixed effects for traits at the sow level}

Primiparous sows had the highest proportion of piglets with an IUGR head morphology (IUGR PROP), the lowest average birth weight (Ave BWT), the smallest variation in birth weight (SD BWT), and were among the highest for survival to processing (SURV PROP; Table 6). Second and third parity sows had the lowest IUGR PROP, which then increased as parity increased, and the highest Ave BWT, which then decreased as parity increased. The within-litter variability in birth weight (SD BWT) increased as parity increased. LITTER SIZE peaked at parities 4 and 5 and then decreased in older sows. The proportion of piglets surviving to processing (SURV PROP) was lowest in the oldest sows. Sow parity had no effect on gestation length (GL).

\section{Heritabilities for traits at the sow level}

Genetic analysis for traits at the sow level was conducted on the full dataset of 1575 records, with all sows having a complete set of records. For all traits, estimates of variance of the animal permanent environmental effect, direct additive genetic effects, and residual variance ranged from 4 to $14 \%, 6$ to $33 \%$ and 59 to $84 \%$ of the phenotypic variance, respectively. Heritabilities for traits at the sow level ranged from low to moderate values (Table 7): PROP IUGR, 0.20 \pm 0.05 ; Ave BWT, $0.33 \pm 0.07$; SD BWT, $0.12 \pm 0.04$; LITTER SIZE, $0.11 \pm 0.05$; PROP SURV, $0.04 \pm 0.03$; and GL, $0.20 \pm 0.05$. Estimates of the genetic correlation of PROP IUGR with the other traits were all moderate to high and negative $(-0.29$ to -0.90$)$, with the exception of the correlation with LITTER SIZE, which was moderate and positive (0.46; Table 7). This shows that as PROP IUGR increases, Ave BWT and PROP SURV decrease. However, it should be noted that, in this dataset, not all estimated genetic correlations were significantly different from zero. PROP IUGR had a moderate $I_{A}$ of $21.6 \%$ but was about $1 \%$ or less for all other traits. All repeatabilities were higher than the estimated heritabilities (Table 7), except for Ave BWT for which they were identical, which indicate that some non-genetic-selection gains can be made for those traits.

\section{Discussion}

Changes in piglet head morphology are known to be a phenotypic indicator of IUGR [IUGR; 34, 35], with IUGR challenge resulting in a specific head morphology that is easy to characterise on farm and under commercial conditions. Our results indicate that genetic gains would be minor when selection is against IUGR at the piglet level; however, selection against the within-litter proportion of IUGR at the sow level would yield better results and may be a suitable trait for an indirect measure of uterine capacity.

At the piglet level, gestation length had a slight effect on IUGR status and birth weight, with a shorter gestation length associated with a higher HEAD CLASS score, i.e. a more IUGR like head morphology and a lower birth weight. In general, shorter gestation lengths are associated with lower birth weights and more intrapartum deaths [49], while longer gestation lengths are often associated with higher birth weights [50]. The association 
Table 6 Effect of sow parity on traits at the sow level

\begin{tabular}{lcccccc}
\hline Parity & $\mathbf{1}$ & $\mathbf{2}$ & $\mathbf{3}$ & $\mathbf{4}$ & $\mathbf{5}$ & $\mathbf{6 +}$ \\
\hline PROP IUGR & $0.19 \pm 0.01^{\mathrm{c}}$ & $0.12 \pm 0.01^{\mathrm{a}}$ & $0.12 \pm 0.01^{\mathrm{a}}$ & $0.16 \pm 0.01^{\mathrm{b}}$ & $0.16 \pm 0.01^{\mathrm{b}}$ & $0.16 \pm 0.01^{\mathrm{b}}$ \\
Ave BWT & $1371 \pm 25^{\mathrm{a}}$ & $1552 \pm 24^{\mathrm{a}}$ & $1552 \pm 24^{\mathrm{a}}$ & $1501 \pm 24^{\mathrm{b}}$ & $1522 \pm 25^{\mathrm{ab}}$ & $1508 \pm 24^{\mathrm{ab}}$ \\
SD BWT & $241 \pm 6^{\mathrm{a}}$ & $271 \pm 6^{\mathrm{c}}$ & $281 \pm 7^{\mathrm{c}}$ & $303 \pm 7^{\mathrm{b}}$ & $308 \pm 8^{\mathrm{bc}}$ & $317 \pm 7^{\mathrm{bc}}$ \\
LITTER SIZE & $13.5 \pm 0.27^{\mathrm{ab}}$ & $13.4 \pm 0.27^{\mathrm{ab}}$ & $13.3 \pm 0.29^{\mathrm{ab}}$ & $14.2 \pm 0.29^{\mathrm{c}}$ & $13.9 \pm 0.32^{\mathrm{bc}}$ & $13.1 \pm 0.31^{\mathrm{a}}$ \\
PROP SURV & $0.90 \pm 0.01^{\mathrm{b}}$ & $0.90 \pm 0.01^{\mathrm{b}}$ & $0.91 \pm 0.01^{\mathrm{b}}$ & $0.89 \pm 0.01^{\mathrm{ab}}$ & $0.90 \pm 0.01^{\mathrm{ab}}$ & $0.88 \pm 0.01^{\mathrm{a}}$ \\
GL & $114.9 \pm 0.11^{\mathrm{a}}$ & $115.0 \pm 0.10^{\mathrm{a}}$ & $115.0 \pm 0.11^{\mathrm{a}}$ & $115.0 \pm 0.11^{\mathrm{a}}$ & $114.9 \pm 0.12^{\mathrm{a}}$ & $115.1 \pm 0.11^{\mathrm{a}}$ \\
\hline
\end{tabular}

PROP IUGR = proportion of piglets with an IUGR head morphology within a litter

AVE BWT $=$ average birth weight within a litter

SD BWT = within-litter standard deviation in birth weight

LITTER SIZE $=$ litter size

PROP SURV $=$ proportion of a litter surviving to processing

$\mathrm{GL}=$ gestation length

All standard errors ( \pm SEM) are from a 6-variate model

Within a line in the table, mean values that share a common character in superscript $(a, b$ and $c)$ do not differ significantly $(P>0.05)$

Table 7 Estimates of phenotypic variance $\left(V_{p}\right)$, residual variance $\left(V_{r}\right)$, genetic variance $\left(V_{g}\right)$, permanent environmental effect of the animal variance $\left(V_{p e}\right)$, and of heritabilities (in italics on diagonal) and phenotypic (above the diagonal) and genetic correlations (below diagonal) for traits at the sow level

\begin{tabular}{lllllll}
\hline & PROP IUGR & Ave BWT & SD BWT & LITTER SIZE & PROP SURV & GL \\
\hline$V_{p}$ & $0.022 \pm 0.0009$ & $64,673 \pm 2786$ & $7325 \pm 273.16$ & $13.11 \pm 0.495$ & $0.016 \pm 0.0006$ & $1.533 \pm 0.0595$ \\
$V_{r}$ & $0.016 \pm 0.0008$ & $38,710 \pm 2008$ & $6107 \pm 308.73$ & $9.82 \pm 0.503$ & $0.014 \pm 0.0007$ & $1.146 \pm 0.0588$ \\
$V_{g}$ & $0.005 \pm 0.0013$ & $21,303 \pm 5084$ & $864 \pm 341.57$ & $1.42 \pm 0.611$ & $0.0007 \pm 0.0005$ & $0.311 \pm 0.0864$ \\
$V_{p e}$ & $0.002 \pm 0.001$ & $4661 \pm 4124$ & $354 \pm 361.40$ & $1.87 \pm 0.671$ & $0.002 \pm 0.0008$ & $0.076 \pm 0.0802$ \\
PROP IUGR & $0.20 \pm 0.05$ & $-0.68 \pm 0.01$ & $0.27 \pm 0.02$ & $0.38 \pm 0.02$ & $-0.20 \pm 0.02$ & $-0.12 \pm 0.03$ \\
Ave BWT (g) & $-0.90 \pm 0.06$ & $0.33 \pm 0.07$ & $-0.07 \pm 0.03$ & $-0.60 \pm 0.02$ & $0.27 \pm 0.02$ & $0.14 \pm 0.03$ \\
SD BWT (g) & $-0.29 \pm 0.24$ & $0.60 \pm 0.18$ & $0.12 \pm 0.04$ & $0.19 \pm 0.03$ & $-0.12 \pm 0.03$ & $-0.05 \pm 0.03$ \\
LITTER SIZE & $0.46 \pm 0.20$ & $-0.59 \pm 0.15$ & $-0.52 \pm 0.29$ & $0.11 \pm 0.05$ & $-0.14 \pm 0.02$ & $-0.19 \pm 0.03$ \\
PROP SURV & $-0.80 \pm 0.32$ & $0.84 \pm 0.29$ & $0.53 \pm 0.41$ & $-0.62 \pm 0.36$ & $0.04 \pm 0.03$ & $0.06 \pm 0.03$ \\
GL (days) & $-0.36 \pm 0.19$ & $0.21 \pm 0.18$ & $-0.18 \pm 0.23$ & $-0.34 \pm 0.23$ & $0.58 \pm 0.32$ & $0.20 \pm 0.05$ \\
Evolvability $\left(I_{A}\right)$ & $23.95 \%$ & $0.96 \%$ & $1.12 \%$ & $0.78 \%$ & $0.09 \%$ & $0.002 \%$ \\
Repeatability & $0.29 \pm 0.03$ & $0.33 \pm 0.07$ & $0.16 \pm 0.04$ & $0.24 \pm 0.03$ & $0.13 \pm 0.04$ & $0.25 \pm 0.04$ \\
\hline
\end{tabular}

All standard errors ( $(\mathrm{SEM})$ are from a 6-variate model

PROP IUGR = proportion of HEAD CLASS 1 piglets within a litter

AVE BWT $=$ average birth weight within a litter

SD BWT = within litter standard deviation in birth weight

PROP SURV = proportion of a litter surviving to processing

$\mathrm{GL}=$ gestation length

between gestation length and HEAD CLASS score may be due to the negative genetic relationship between gestation length and litter size at the maternal level, with larger litters being associated with shorter gestation lengths, and the negative genetic relationship between litter size and proportion of IUGR in a litter, with larger litters being associated with a higher proportion of IUGR head morphology and lower birth weight piglets. It should be noted that not all genetic correlation estimates were significantly different from zero (with high standard errors). Studies with more animals and different populations are necessary to elucidate furthermore these relationships and their impact on IUGR incidence. Our heritability estimate for gestation length and the associated genetic correlations fit squarely with values in the literature, i.e. heritabilities for gestation length ranging from 0.14 to 0.30 [51-53], with a negative genetic 
correlation with litter size [51] and a positive genetic correlation with average birth weight [53].

Our findings agree with those from other studies in which first parity sows produce piglets with lower average birth weight than older parities. Sows are not physically mature during their first gestation and do not reach maturity until approximately 18 months of age [54], although some studies have shown that body growth continues past the 6th parity [55]. Because of this, young sows are 'selfish' in terms of nutrient partitioning, keeping more of their available nutrients for somatic body growth rather than offspring growth. This results in more nutritional retardation and thus lower birth weights and a higher proportion of piglets with an IUGR head morphology. In addition, birth weight varies less within first parity litters because more of these litters are uniformly small. It is interesting to note that, in our study, second parity sows do not follow the biological logic in energy partitioning, since they are expected to still have significant somatic growth and thus to be intermediate between first and third parity sows.

Litter size is a significant predictor of piglet IUGR head morphology. Recent selection pressure for increased litter size at birth has resulted in more piglets being born with a low birth weight $[12,13,56,57]$, lower physiological maturity at birth [58], and higher rate of intrauterine growth retardation [14]. The estimated heritability for litter size, in our study, is similar to those reported for other polytocous species $[1,3,4,59,60]$, and typical for a composite reproductive trait. We also found that litter size and average birth weight at the sow level were strongly negatively genetically correlated and acted antagonistically on mother and offspring, which is in agreement with other studies $[1,3,4,60]$. This antagonistic relationship, with a presumed negative genetic correlation between number and size of offspring is thought to constrain the evolution of litter size and average birth weight [2].

In theory, genetic correlations between life history traits are expected to be negative [61] and our estimate of the genetic correlation between litter size and average birth weight was high and negative. An increase in average birth weight has been linked to a reduced risk of mortality [62], which explains our high and positive genetic correlation estimate between average birth weight and within-litter proportion of piglets surviving till processing. The within-litter standard deviation in birth weight has also been linked to a greater odds-ratio for mortality of piglets [62], with this within-litter weight distribution already established by the end of the embryonic stage of gestation [63]. In our study, litter size was highly negatively genetically correlated with the proportion of piglets surviving till processing (18-24 h after birth), negatively genetically correlated with average birth weight, and positively genetically correlated with the within-litter proportion of IUGR piglets, which suggests that bigger the litter size, the lower the average birth weight, the greater the proportion of IUGR piglets, and the lower the proportion of piglets surviving until $24 \mathrm{~h}$ after birth. Of particular interest is the highly negative genetic correlation between the proportion of IUGR-affected piglets and the proportion of piglets surviving until processing, which indicates that selection against the within-litter proportion of IUGR-affected piglets would result in an associated increase in the within-litter proportion of piglets surviving until $24 \mathrm{~h}$ of age.

Uterine capacity can be defined as the number of conceptuses a uterus can successfully carry to term [64]. In general, the number of living conceptuses that the uterus is capable of supporting is larger in early gestation than later [38], while in later gestation intrauterine competition for the establishment of adequate surface area for nutrition exchange between foetal and maternal circulations may act to limit litter size [14]. However, it is often difficult to measure uterine capacity directly on farm and most selection programmes use indirect measures of uterine capacity, such as increasing litter size, selection on the number of live born piglets at day 5 [65] or on litter weight [66].

In our study, phenotypes were collected on the piglets and, thus, the underlying mechanism resulting in reduced incidences of IUGR is unclear since measures to characterise uterine morphology and physiology were not available. Selection for reduced rates of IUGR may result in improving the development of the folded placental-epithelial/maternal-epithelial bilayer and fold depth, i.e. the maternal foetal interactive surface [38], or of a more efficient placenta. However, a comparison of placental efficiency (the grams of foetus that could be supported by the grams of placenta) between Meishan and Yorkshire breeds highlighted that the greater placental efficiency of Meishan sows was a result of smaller conceptuses that contained fewer cells, compared with Yorkshire conceptuses regardless of uterine environment [67]. In addition, although selection for placental efficiency may result in greater litter size without decreasing piglet viability [68], the resulting piglets had a $20 \%$ lower birth weight than those of control lines. An alternative effect of selection for lower rates of IUGR may be more evenly spaced embryos. Lents et al. [69] reported negative relationships of ovulation rate with embryonic spacing and with empty space around the embryonic-placental unit, which both indicate crowded uterine conditions. Other studies have shown that mouse lines that lack lysophosphatidic acid, a phospholipid involved in uterine peristaltic movements that facilitate embryo separation [69], have blastocysts that remain clustered in the vicinity of the cervix, 
whereas non-deficient lines have blastocysts that are evenly distributed along the uterine horns [70].

Studies that specifically investigated different aspects of uterine capacity reported that genetic selection of gilts for high uterine capacity led to greater litter size and overall litter weight, but not to a greater average birth weight [71], and that selection for increased placental efficiency did not increase litter size [72]. Lents et al. [73] investigated the phenotypic differences of the reproductive tract in prepubertal gilts using transrectal ultrasound and found that, overall, selection for increased uterine capacity resulted in larger ovaries and uterine horn diameter but that there was no discernible difference in these traits between gilts selected for increased uterine capacity and control gilts at 130, 150 or 170 days, which suggests that uterine capacity is difficult to select for prior to first breeding.

Attempts to identify candidate genes [74] and chromosomal regions that harbour quantitative trait loci [75] found no definitive associations between major genes or markers for reproductive traits, although more recent studies have since identified some potential genetic markers for various reproductive traits average birth interval [76], teat number [77], e.g. age at puberty and reproductive longevity [78].

Another approach to estimate uterine capacity is to use the unilateral hysterectomy-ovariectomy (UHO) model. Christenson et al. [79] concluded that UHO gilts that carried the largest litters had greater uterine capacity. Regardless of the mechanism underlying selection for increased uterine capacity, this variability indicates that there is additive genetic variance in this trait.

In our study, the heritability of IUGR head morphology at the piglet level was low, i.e. 0.01. The proportion of maternal variance was also low, i.e. 0.03. In contrast, the heritability for birth weight was higher at 0.10 , while the proportion of maternal variance was 0.14 . However, it should be noted that, in this dataset, the direct heritability of the continuous birth weight trait was low compared with other studies $[80,81]$. Sire effects are also known to affect piglet birth weight [82], but we did not find any significant effect of the piglet genotype $(\mathrm{L} \times \mathrm{LW}$ or $\mathrm{L} \times \mathrm{WD})$ and, therefore, removed it from the model.

Binary traits tend to have a lower heritability than continuous traits by virtue of the binary scale and its lack of intermediate values, with the bias and precision of the estimation methods, depending on the incidence of the phenotype under study [83]. The conventional solution to binary traits is to treat the binary trait as if it was continuous, quantify the heritability and adjust the estimates based on the prevalence of the trait in the population. In our study, since the direct heritability for traits at the piglet level was sufficiently low, no further adjustments were conducted and an alternative trait (at the sow level) was investigated.

In general, traits with the strongest influence on survival have the lowest heritabilities [84-86]. There are two possible reasons for this: (1) fitness traits limit the evolutionary potential by exhausting the genetic variation for traits in direct proportion to their effect on fitness [85, 87]; or (2) fitness traits have greater residual variance $[40,42,86,88]$. In our study, the residual variance of the IUGR head morphology trait at the piglet level was high, i.e. $90 \%$ of the phenotypic variance, compared to the $5 \%$ attributable to genetics, which suggests the second explanation may be more appropriate [89].

If offspring fitness depends on the piglet's IUGR head morphology and associated effects, piglet head morphology is expected to have a higher evolvability than other morphological traits. However, an evolvability of $\sim 8 \%$ was found for IUGR head morphology, which indicates that the potential phenotypic variation for this trait is small. In addition, the direct narrow-sense heritability was low at 0.01 due to the high residual variance and, thus, direct selection against IUGR head morphology at the piglet level would be slow. If selection against intrauterine growth retardation at the piglet level is not suitable/appropriate, is selection at the sow level a better prospect? Heritability of the proportion of IUGR-affected piglets in a litter was approximately 0.20 . The variance percentage for the permanent environmental effect of the sow was low at $9 \%$, while the residual variance accounted for $72 \%$ of the phenotypic variance. The evolvability for the within-litter IUGR proportion was approximately $22 \%$, while the narrow-sense heritability was 0.20 . The repeatability of the proportion of IUGR-affected piglets in a litter was $0.29 \pm 0.03$, which suggests that, although most of the improvement may be achieved via genetic selection some improvement can be obtained via the maternal environment.

Repeatability is the proportion of total variance in multiple measurements that is due to individual differences [90] and is useful for quantifying the extent to which an individual's performance remains consistent over time [91-93]. The generally low repeatability of the traits analysed in this study may indicate practical problems that are associated with trait measurement or that the timeframe for measurement was not relevant [94]. This may be true for young sows, with primiparous sows having the highest proportion of IUGR-affected piglets and the lowest average birth weight compared with older sows, which is most likely due to the biology behind energy partitioning. Thus, these findings suggest that these traits should be treated as different traits in primiparous and older animals. However, the lower repeatabilities may also show a lack of independence for successive 
measurements [90] since, at each successive farrowing, the traits are context-dependent on litter size. The number of conceptuses will differ at each service for many reasons, i.e. poor/good sow body condition at service, poor quality semen sample, or reduced quality of available oocytes in older parity sows.

In this study, we show that selection against intrauterine growth retardation and an associated increase in the proportion of piglets surviving until $24 \mathrm{~h}$, can be effective. In addition, selection for component traits of female reproduction/fertility does not appear to negatively affect boar semen quality [95], which means that the withinlitter proportion of IUGR-affected piglets trait has potential application in the field. Its measurement is based on a visual score $[34,35]$, which is easily collected under commercial conditions. This indicates that selection against the within-litter proportion of IUGR-affected piglets, with the corresponding genetic gains in associated traits, is a suitable trait for use in commercial breeding programs.

In conclusion, selection against intrauterine growth retardation is possible at the maternal level, through the within-litter proportion of IUGR-affected piglets trait. Inclusion of litter size in addition to the withinlitter proportion of IUGR-affected piglets in the breeding programme should maintain current litter sizes. An important and beneficial consequence of selection on low levels of within-litter proportions of IUGR-affected piglets would be a corresponding increase in the survival of piglets to $24 \mathrm{~h}$ of age.

\section{Authors' contributions}

SMM and SAE conceived the study and participated in the design and coordination. SMM carried out the data collection, performed the statistical analyses and drafted the manuscript. GAW provided facilities and additional data. All authors read and approved the final manuscript.

\section{Author details}

${ }^{1}$ Agriculture, School of Natural and Environmental Sciences, University of Newcastle, Newcastle upon Tyne NE1 7RU, UK. ${ }^{2}$ JSR Genetics, Southburn, Driffield, East Yorkshire YO25 9ED, UK.

\section{Acknowledgements}

This work was conducted under the PROHEALTH project. PROHEALTH has received funding from the European Union's Seventh Framework Programme for research, technological development and demonstration under Grant Agreement No. 613574. The authors wish to thank the staff at the JSR multiplier unit for the animal husbandry and technical assistance.

\section{Competing interests}

The authors declare that they have no competing interests.

\section{Publisher's Note}

Springer Nature remains neutral with regard to jurisdictional claims in published maps and institutional affiliations.

Received: 5 October 2017 Accepted: 10 September 2018 Published online: 18 September 2018

\section{References}

1. Mappes T, Koskela E. Genetic basis of the trade-off between offspring number and quality in the bank vole. Evolution. 2004;58:645-50.

2. Stearns SC. The evolution of life histories. Oxford: Oxford University Press; 1992.

3. Oksanen TA, Koskela E, Mappes T. Hormonal manipulation of offspring number: maternal effort and reproductive costs. Evolution. 2002;56:1530-7.

4. Wolf JB, Wade MJ. On the assignment of fitness to parents and offspring: whose fitness is it and when does it matter? J Evol Biol. 2001;14:347-56.

5. Zera AJ, Harshman LG. The physiology of life history trade-offs in animals. Annu Rev Ecol Evol Syst. 2001;32:95-126.

6. Rothschild MF, Ruvinsky A. The genetics of the pig. 2nd ed. Wallingford: CAB. International; 2011.

7. Vinet A, Drouilhet L, Bodin L, Mulsant P, Fabre S, Phocas F. Genetic control of multiple births in low ovulating mammalian species. Mamm Genome. 2012;23:727-40.

8. Spitschak M, Langhammer M, Schneider F, Renne U, Vanselow J. Two high-fertility mouse lines show differences in component fertility traits after long-term selection. Reprod Fertil Dev. 2007;19:815-21.

9. van der Waaij EH, Hazeleger W, Soede NM, Laurenssen BFA, Kemp B. Effect of excessive, hormonally induced intrauterine crowding in the gilt on fetal development on day 40 of pregnancy. J Anim Sci. 2010;88:2611-9.

10. Dziuk PJ. Effect of number of embryos and uterine space on embryo survival in the pig. J Anim Sci. 1968;27:673-6.

11. Silalahi P, Tribout T, Prunier A, Billon Y, Gogue J, Bidanel JP. Estimation of the effects of selection on French Large White reproductive performance using frozen semen. J Anim Sci. 2016;94:3655-62.

12. Campos PH, Silva BAN, Donzele JL, Oliveira RFM, Knol EF. Effects of sow nutrition during gestation on within-litter birth weight variation: a review. Animal. 2012:6:797-806

13. Milligan BN, Dewey CE, de Grau AF. Neonatal-piglet weight variation and its relation to pre-weaning mortality and weight gain on commercial farms. Prev Vet Med. 2002;56:119-27.

14. Foxcroft GR, Dixon WT, Novak S, Putman CT, Town SC, Vinsky MDA. The biological basis for prenatal programming of postnatal performance in pigs. J Anim Sci. 2006;84:E105-12.

15. Town SC, Putman CT, Turchinsky NJ, Dixon WT, Foxcroft GR. Number of conceptuses in utero affects porcine fetal muscle development. Reproduction. 2004;128:443-54.

16. Town SC, Patterson JL, Pereira CZ, Gourley G, Foxcroft GR. Embryonic and fetal development in a commercial dam-line genotype. Anim Reprod Sci. 2005;85:301-16.

17. Roza SJ, Steegers EAP, Verburg BO, Jaddoe VWV, Moll HA, Hofman A, et al. What is spared by fetal brain-sparing? Fetal circulatory redistribution and behavioral problems in the general population. Am J Epidemiol. 2008;168:1145-52.

18. McMillen IC, Robinson JS. Developmental origins of the metabolic syndrome: prediction, plasticity, and programming. Physiol Rev. 2005;85:571-633.

19. Foxcroft GR, Dixon WT, Dyck MK, Novak S, Harding JC, Almeida FC. Prenatal programming of postnatal development in the pig. Soc Reprod Fertil Suppl. 2009;66:213-31.

20. D'Inca R, Che L, Thymann T, Sangild PT, Le Huërou-Luron I. Intrauterine growth restriction reduces intestinal structure and modifies the response to colostrum in preterm and term piglets. Livest Sci. 2010;133:20-2.

21. Chen F, Wang TJ, Feng CP, Lin G, Zhu YH, Wu GY, et al. Proteome differences in placenta and endometrium between normal and intrauterine growth restricted pig fetuses. PLoS One. 2015;10:e0142396.

22. Wang T, Huo YJ, Shi FX, Xu RJ, Hutz RJ. Effects of intrauterine growth retardation on development of the gastrointestinal tract in neonatal pigs. Biol Neonate. 2005;88:66-72.

23. Wang TJ, Liu C, Feng CP, Wang XQ, Lin G, Zhu YH, et al. IUGR alters muscle fiber development and proteome in fetal pigs. Front Biosci (Landmark Ed). 2013;18:598-607.

24. Nissen PM, Oksbjerg N. Birth weight and postnatal dietary protein level affect performance, muscle metabolism and meat quality in pigs. Animal. 2011:5:1382-9

25. Krueger R, Derno M, Goers S, Metzler-Zebeli BU, Nuernberg G, Martens K, et al. Higher body fatness in intrauterine growth retarded juvenile pigs 
is associated with lower fat and higher carbohydrate oxidation during ad libitum and restricted feeding. Eur J Nutr. 2014;53:583-97.

26. Ashworth CJ. Late pregnancy: the effects of intra-uterine life on production traits in offspring. Anim Front. 2013;3:62-7.

27. De Vos M, Che L, Huygelen V, Willemen S, Michiels J, Van Cruchten S, et al. Nutritional interventions to prevent and rear low-birthweight piglets. J Anim Physiol Anim Nutr (Berl). 2014;98:609-19.

28. Oksbjerg N, Nissen PM, Therkildsen M, Moller HS, Larsen LB, Andersen $M$, et al. Meat science and muscle biology symposium: in utero nutrition related to fetal development, postnatal performance, and meat quality of pork. J Anim Sci. 2013;91:1443-53.

29. Wallace JM, Bourke DA, Aitken RP, Milne JS, Hay WW Jr. Placental glucose transport in growth-restricted pregnancies induced by overnourishing adolescent sheep. J Physiol. 2003;547:85-94.

30. Wu GY, Bazer FW, Cudd TA, Meininger CJ, Spencer TE. Maternal nutrition and fetal development. J Nutr. 2004;134:2169-72.

31. Matheson SM, Bunger L, Dwyer CM. Genetic parameters for fitness andneonatal behavior traits in sheep. Behav Genet. 2012;42:899-911.

32. Baxter EM, Jarvis S, D'Eath RB, Ross DW, Robson SK, Farish M, et al. Investigating the behavioural and physiological indicators of neonatal survival in pigs. Theriogenology. 2008;69:773-83.

33. Luna ME, Quintero FA, Cesani MF, Fucini MC, Prio V, Guimarey LM, et al. Craniofacial catch-up growth in intrauterine growth retarded rats following postnatal nutritional rehabilitation. Clin Exp Obstet Gynecol. 2014;41:530-3.

34. Hales J, Moustsen VA, Nielsen MBF, Hansen CF. Individual physical characteristics of neonatal piglets affect preweaning survival of piglets born in a noncrated system. J Anim Sci. 2013;91:4991-5003.

35. Chevaux E, Sacy A, Le Truet Y, Martineau G. Intra-uterine growth retardation (IUGR): morphological and behavioural description. In: Proceedings of the 21st international pig veterinary society congress: 18-21 July 2010. Vancouver. 2010, p. 209

36. Bazer FW, Clawson AJ, Robison OW, Ulberg LC. Uterine capacity in gilts. J Reprod Fertil. 1969;18:121-4.

37. Bazer FW, Robison OW, Clawson AJ, Ulberg LC. Uterine capacity at two stages of gestation in gilts following embryo superinduction. J Anim Sci. 1969:29:30-4.

38. Vallet JL, McNeel AK, Miles JR, Freking BA. Placental accommodations for transport and metabolism during intra-uterine crowding in pigs. J Anim Sci Biotechnol. 2014;5:55.

39. Webel SK, Dziuk PJ. Effect of stage of gestation and uterine space on prenatal survival in the pig. J Anim Sci. 1974;38:960-3.

40. Hansen TF, Houle D. Measuring and comparing evolvability and constraint in multivariate character. J Evol Biol. 2008:21:1201-19.

41. Houle D. Comparing evolvability and variability of quantitative traits. Genetics. 1992;130:195-204.

42. Hansen TF, Pelabon C, Houle D. Heritability is not evolvability. Evol Biol. 2011;38:258-77.

43. Kirschner M, Gerhart J. Evolvability. Proc Natl Acad Sci USA. 1998:95:8420-7.

44. Gilmour AR, Gullis BR, Welham SJ, Thompson R. ASReml user quide release 2.0. Hemel Hempstead: VSN International Ltd. 2006.

45. Bryant EH. On use of logarithms to accommodate scale. Syst Biol. 1986:35:552-9.

46. Gianola D, Foulley JL. Sire evaluation for ordered categorical data with a threshold model. Genet Sel Evol. 1983;15:201-24.

47. Harville DA, Mee RW. A mixed-model procedure for analyzing ordered categorical data. Biometrics. 1984;40:393-408.

48. Purvis IW, Hillard M. Biology and genetics of reproduction. In: Piper LR, Ruvinsky A, editors. The genetics of sheep. New York: CAB; 1997. p. 375-94.

49. Mota-Rojas D, Fierro R, Roldan-Santiago P, Orozco-Gregorio H, GonzalezLozano M, Bonilla $\mathrm{H}$, et al. Outcomes of gestation length in relation to farrowing performance in sows and daily weight gain and metabolic profiles in piglets. Anim Prod Sci. 2015;55:93-100.

50. Vermeulen L, Van Beirendonck S, Bulens A, Van Thielen J, Driessen B. Sire line of pigs affects weaning weight, growth performance, and carcass characteristics of offspring. J Anim Sci. 2016;94:4360-8.

51. Zhang T, Wang LG, Shi HB, Yan H, Zhang LC, Liu X, et al. Heritabilities and genetic and phenotypic correlations of litter uniformity and litter size in Large White sows. J Integr Agric. 2016;15:848-54.
52. Hanenberg EHAT, Knol EF, Merks JWM. Estimates of genetic parameters for reproduction traits at different parities in Dutch Landrace pigs. Livest Prod Sci. 2001:69:179-86.

53. Rydhmer L, Lundeheim N, Canario L. Genetic correlations between gestation length, piglet survival and early growth. Livest Sci. 2008;115:287-93.

54. Reiland S. Growth and skeletal development of the pig. Acta Radiol Suppl. 1978:358:15-22.

55. Simmins PH, Edwards SA, Spechter HH. Growth and body condition of sows given different feeding regimes during the rearing stage and through 8 parities when housed in groups with straw bedding. Anim Prod. 1994;58:271-83.

56. Baxter EM, Rutherford KMD, D'Eath RB, Arnott G, Turner SP, Sandøe P, et al. The welfare implications of large litter size in the domestic pig II: management factors. Anim Welfare. 2013:22:219-38.

57. Rutherford KMD, Baxter EM, D'Eath RB, Turner SP, Arnott G, Roehe R, et al. The welfare implications of large litter size in the domestic pig I: biological factors. Anim Welfare. 2013;22:199-218.

58. Canario L, Rydhmer L, Gogue J, Tribout T, Bidanel JP. Estimation of genetic trends from 1977 to 1998 for farrowing characteristics in the French Large White breed using frozen semen. Animal. 2007:1:929-38.

59. Schroderus E, Koivula M, Koskela E, Mappes T, Oksanen TA, Poikonen T. Can number and size of offspring increase simultaneously? a central lifehistory trade-off reconsidered. BMC Evol Biol. 2012;12:44.

60. Wilson AJ, Pilkington JG, Pemberton JM, Coltman DW, Overall ADJ, Byrne $\mathrm{KA}$, et al. Selection on mothers and offspring: whose phenotype is it and does it matter? Evolution. 2005;59:451-63.

61. Lande R. A quantitative genetic theory of life history evolution. Ecology. 1982;63:607-15.

62. Roehe R, Kalm E. Estimation of genetic and environmental risk factors associated with pre-weaning mortality in piglets using generalized linear mixed models. Anim Sci. 2000;70:227-40.

63. van der Lende T, Hazeleger W, de Jager D. Weight distribution within litters at the early foetal stage and at birth in relation to embryonic mortality in the pig. Livest Prod Sci. 1990;26:53-65.

64. Ford SP, Vonnahme KA, Wilson ME. Uterine capacity in the pig reflects a combination of uterine environment and conceptus genotype effects. J Anim Sci. 2002;80:E66-73.

65. Freking BA, Lents $C A$, Vallet JL. Selection for uterine capacity improves lifetime productivity of sows. Anim Reprod Sci. 2016;167:16-21.

66. Dhakal S, Auckland C, Huang Y, Ambros B, Duke T, Wilson DG, et al. Uterine spaciousness during embryo and fetal development in multiparous sows improves birth weight and postnatal growth performance. Livest Sci. 2013;153:154-64.

67. Wilson ME, Biensen NJ, Youngs CR, Ford SP. Development of Meishan and Yorkshire littermate conceptuses in either a Meishan or Yorkshire uterine environment to day 90 of gestation and to term. Biol Reprod. 1998:58:905-10.

68. Wilson ME, Biensen NJ, Ford SP. Novel insight into the control of litter size in pigs, using placental efficiency as a selection tool. J Anim Sci. 1999;77:1654-8.

69. Da Silva $C L$, van den Brand H, Laurenssen BF, Broekhuijse ML, Knol EF, Kemp B, et al. Relationships between ovulation rate and embryonic and placental characteristics in multiparous sows at 35 days of pregnancy. Animal. 2016;10:1192-9.

70. Chen Q, Zhang Y, Elad D, Jaffa AJ, Cao Y, Ye X, et al. Navigating the site for embryo implantation: biomechanical and molecular regulation of intrauterine embryo distribution. Mol Aspects Med. 2013;34:1024-42.

71. Hama K, Aoki J, Inoue A, Endo T, Amano T, Motoki R, et al. Embryo spacing and implantation timing are differentially regulated by LPA3-mediated lysophosphatidic acid signaling in mice. Biol Reprod. 2007;77:954-9.

72. Vallet JL, Leymaster KA, Christenson RK. The influence of uterine function on embryonic and fetal survival. J Anim Sci. 2002;80:E115-25.

73. Mesa H, Cammack KM, Safranski TJ, Green JA, Lamberson WR. Selection for placental efficiency in swine: conceptus development. J Anim Sci. 2012;90:4217-22.

74. Lents CA, Cushman RA, Freking BA. Measures of the ovaries and uterus during development of gilts selected for differences in uterine capacity. J Anim Sci. 2014;92:2433-9.

75. Linville RC, Pomp D, Johnson RK, Rothschild MF. Candidate gene analysis for loci affecting litter size and ovulation rate in swine. J Anim Sci. 2001;79:60-7. 
76. Cassady JP, Johnson RK, Pomp D, Rohrer GA, Van Vleck LD, Spiegel EK, et al. Identification of quantitative trait loci affecting reproduction in pigs. J Anim Sci. 2001;79:623-33.

77. Schneider JF, Miles JR, Brown-Brandl TM, Nienaber JA, Rohrer GA, Vallet JL. Genomewide association analysis for average birth interval and stillbirth in swine. J Anim Sci. 2015;93:529-40.

78. Rohrer GA, Nonneman DJ. Genetic analysis of teat number in pigs reveals some developmental pathways independent of vertebra number and several loci which only affect a specific side. Genet Sel Evol. 2017;49:4

79. Tart JK, Johnson RK, Bundy JW, Ferdinand NN, McKnite AM, Wood JR, et al. Genome-wide prediction of age at puberty and reproductive longevity in sows. Anim Genet. 2013;44:387-97.

80. Christenson RK. Ovulation rate and embryonic survival in Chinese Meishan and white crossbred pigs. J Anim Sci. 1993;71:3060-6.

81. Canario L, Cantoni E, Le Bihan E, Caritez JC, Billon Y, Bidanel JP, et al. Between-breed variability of stillbirth and its relationship with sow and piglet characteristics. J Anim Sci. 2006;84:3185-96.

82. Roehe R, Shrestha NP, Mekkawy W, Baxter EM, Knap PW, Smurthwaite KM, et al. Genetic analyses of piglet survival and individual birth weight on first generation data of a selection experiment for piglet survival under outdoor conditions. Livest Sci. 2009;121:173-81.

83. Damgaard LH, Rydhmer L, Lovendahl P, Grandinson K. Genetic parameters for within-litter variation in piglet birth weight and change in within-litter variation during suckling. J Anim Sci. 2003;81:604-10.

84. de Villemereuil P, Gimenez O, Doligez B. Comparing parent-offspring regression with frequentist and Bayesian animal models to estimate heritability in wild populations: a simulation study for Gaussian and binary traits. Methods Ecol Evol. 2013;4:260-75.

85. Mousseau TA, Roff DA. Natural selection and the heritability of fitness components. Heredity (Edinb). 1987;59:181-97.
86. Falconer DS, Mackay TFC. Introduction to quantitative genetics. 4th ed. Harlow: Longman Group Limited; 1996.

87. Merilä J, Sheldon BC. Genetic architecture of fitness and nonfitness traits: empirical patterns and development of ideas. Heredity (Edinb). 1999:83:103-9.

88. Teplitsky C, Mills JA, Yarrall JW, Merilä J. Heritability of fitness components in a wild bird population. Evolution. 2009;63:716-26.

89. Price T, Schluter D. On the low heritability of lie-history traits. Evolution. 1991:45:853-61.

90. Kristensen TN, Hoffmann AA, Pertoldi C, Stronen AV. What can livestock breeders learn from conservation genetics and vice versa? Front Genet. 2015;6:38.

91. Dohm MR. Repeatability estimates do not always set an upper limit to heritability. Funct Ecol. 2002;16:273-80.

92. Lessells CM, Boag PT. Unrepeatable repeatabilities-a common mistake. Auk. 1987;104:116-21.

93. Boake CRB. Repeatability -its role in evolutionary studies of matingbehavior. Evol Ecol. 1989;3:173-82.

94. Hayes JP, Jenkins SH. Individual variation in mammals. J Mammal. 1997;78:274-93.

95. Freking BA, Purdy PH, Spiller SF, Welsh CS, Blackburn HD. Boar sperm quality in lines of pigs selected for either ovulation rate or uterine capacity. J Anim Sci. 2012;90:2515-23.
Ready to submit your research? Choose BMC and benefit from:

- fast, convenient online submission

- thorough peer review by experienced researchers in your field

- rapid publication on acceptance

- support for research data, including large and complex data types

- gold Open Access which fosters wider collaboration and increased citations

- maximum visibility for your research: over 100M website views per year

At BMC, research is always in progress.

Learn more biomedcentral.com/submissions 